\title{
Research and Application of WSN Technology in the Contact Points of Distribution Transformer
}

\author{
Yan-Fei Su, Chen-Xu Zhao, Long Xu, Huan-Ping Ye, and Heng Xu
}

\begin{abstract}
This article describes the principles and characteristics of wireless temperature measurement technology build a real-time online monitoring wireless temperature measurement system. The wireless temperature sensor is installed in the contact point of the distribution transformer to measure the contact temperature. Real-time temperature data obtained through remote wireless network with varying contact point. Guide bar contact and leads to the cable line temperature monitoring to ensure the security of electricity supply distribution transformers. The monitoring system is applied in practice cases a significant effect and economic benefits.
\end{abstract}

Index Terms-Temperature, transformer, WSN, monitoring, application.

\section{INTRODUCTION}

Distribution transformer is to ensure the safety of power system operation and people's living one of the important equipment for reliable electricity. Distribution transformers in the long-term outdoor run, the high side and low side of the point of contact sites due to the poor quality of the joint, the contact resistance is too large, copper and aluminum transition clamp oxidation or transformer overloading running. Outdated in the load current flow will produce fever phenomenon, the temperature of the heat-generating part no effective monitoring and processing will decline caused by the mechanical strength of the metal materials, the aging of the insulating material and may lead to the breakdown, eventually leading to the occurrence of the accident.

Online measuring and monitoring the temperature distribution transformers contact is a powerful means to avoid the accident and control failure, has a very important significance for power users normal use of electricity, improve the operational reliability of the power system and the degree of automation.

In recent years, the distribution transformers in China's Inner Mongolia region has many contact points overheat accident occurred, resulting in local factories, enterprises blackout solve overheating problems of the point of contact is the key to put an end to such incidents occurred, to achieve real-time monitoring of the temperature of the contact point becomes an important means to guarantee the safe operation of distribution transformers [1].

This article describes the development of wireless sensor temperature measuring device, and switch cabinets online monitoring and early warning system. Contact systems

Manuscript received March 8, 2013; revised June 6, 2013.

The authors are with the Inner Mongolia Electric Power Group Co., Ltd. (e-mail: bmzcx99@sina.com; bmxx117611@sina.com; yanhuanping@sina.com; nmbmxuheng@163.com). connected to it through the distribution transformer equipment for monitoring and early warning, using GPRS or Wi-Fi communication, remote monitoring and temperature measurement, distribution transformer monitoring security and with radio area electricity load distribution capacity and security and defense capacity.

\section{The Transformer Contact Point Temperature MEASUREMENT METHOD}

\section{A. Commonly Used Temperature Measurement Method}

At present, the contact point of the distribution transformer also no large-scale online monitoring, rely mainly on human use handheld infrared camera inspection, Long working hours, low efficiency, the problem cannot be found. The voltage level of the distribution network is generally $10 \mathrm{kV}$, accompanied by a high-voltage, high-current and high magnetic field around the distribution transformer, conventional temperature measurement means cannot solve the electrical safe distance, and it is difficult to be applied in practice. Usually some scientific research units and enterprises to use the monitoring methods are:

\section{1) The use of color chip}

The principle varies with the temperature of the different color of the color chip, Work site can be judged based on the color of the color chip to the approximate temperature range of the contact point, the drawback is the low accuracy, and remote monitoring cannot be performed.

\section{2) The traditional contact measurement}

Contact temperature sensor temperature measurement (platinum resistance, thermocouple, integrated digital temperature sensor, etc.), you need to install the sensors on the contact point of the distribution transformer signal transmitted through the signal cable.

\section{3) Using a thermal infrared detector technology}

Thermal infrared measuring device, wide measurement range, high accuracy can be achieved non-contact measurement, the disadvantage is expensive, is not conducive to large-scale measurements.

\section{4) Fiber-optic thermometry technology}

Optical Temperature sensor using optical fiber to measure temperature, do not accept the high-voltage, high-current, high magnetic field, and the environment interference, installation requires the installation of the protective cover and heat-resistant materials.

\section{B. WSN Technology Temperature Measurement}

Wireless sensor network (Wireless Sensor Network, WSN) 
is deployed in the monitoring area a lot of cheap micro sensor nodes, formed a multi-hop self-organizing network through wireless communication system. It can capture a digital signal of the device to wireless gateway to be transmitted to the monitoring center via a wireless sensor network, fed directly into the computer for analysis and processing. Through the gateway, the control parameter information is transmitted to a node in a wireless manner. Acquisition and processing module of the data conditioning of the sensor output of the weak signal after amplification, filtering and conditioning circuit, sent to the analog-to-digital converter, into a digital signal, sent to the main processor for digital signal processing, and calculate the sensor RMS displacement values and the like. [2]

\section{Analysis of Temperature Measurement Methods}

1) The traditional color chip thermometry way data collection is not convenient, low accuracy, cannot achieve the wireless transmission of data should not be used in the temperature measurement of the distribution transformer;

2) Traditional touch sensor through a cable to connect sensors, and inconvenient to install, and easy to cause the interphase short-circuiting due to the narrow space. Cannot remotely transmit data signal lines;[3]

3) Fiber-optic temperature measurement methods used more often, Optical Temperature measuring instrument using fiber-optic signal transmission fiber has an easy to fold, easy to break, not heat shortcomings, the wiring is difficult, and the higher cost of construction and maintenance difficulties, does not apply to the contact point of the power transformer;

4) Infrared thermometer for non-contact temperature measurement, susceptible to electromagnetic interference environment and surrounding outdoor installation, the installation inconvenience (the probe needs to maintain a safe distance with the measured object, and the need is on the surface of the measured object).

\section{TEMPERATURE MONITORING SySTEM WORKS}

Temperature monitoring system consists of a wireless temperature sensor, a temperature monitor and temperature monitoring main station (Fig. 1).

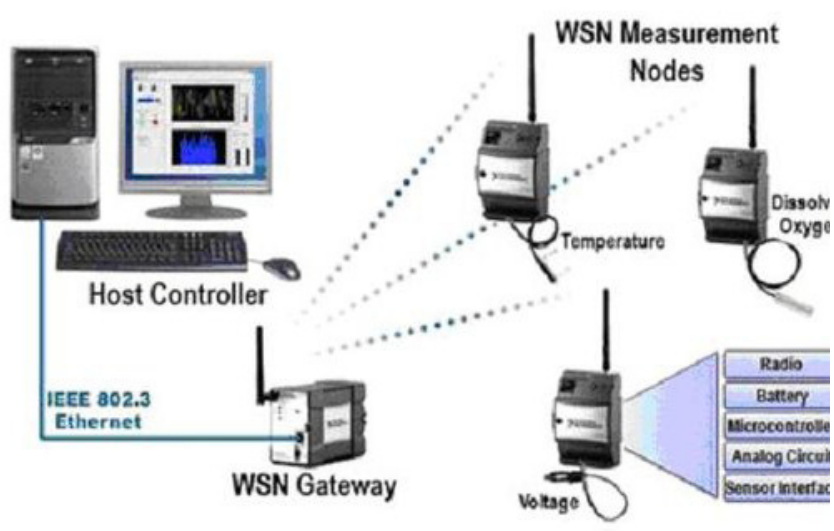

Fig. 1. Temperature monitoring system structure
The system works: wireless temperature sensor per minute measured once the operating temperature of the monitoring points, and an ambient temperature sensor will automatically measure the ambient temperature, these temperature data by the $2.4 \mathrm{GHz}$ wireless channel to the main station, the main station to save these data. main station through relative temperature rise of Comparative and Environmental the relatively temperature rise of the indoor and outdoor atmosphere, analysis of possible overheating, ahead of warning signal to alert the management staff for processing.

\section{A. Wireless Temperature Sensor}

Wireless temperature sensor for measuring the temperature of the surface of the charged objects, such as exposed live parts within the high voltage switchgear, the contact point of the transformer and the cable operating temperature. Wireless temperature sensor is a digital integrated temperature sensor, the signal processing circuit, microcontroller circuit, wireless debug interface and a lithium battery power supply circuit shown in Fig. 2, micro-controller of the temperature signal through a $2.4 \mathrm{G}$ wireless sensor network to temperature monitor.

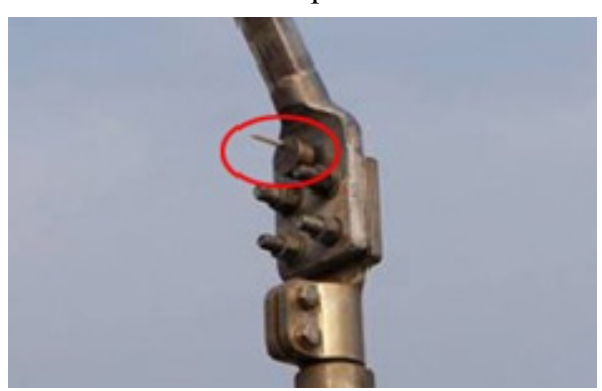

Fig. 2. Temperature sensor installation location

\section{B. Temperature Monitor}

The temperature monitor can support six wireless temperature sensor display with backlit LCD display 6 channel temperature data can be displayed simultaneously, which can manage 32 wireless sensors, and temperature alarm and fault indication function of temperature measuring points. Temperature monitor isolated RS485 bus, can be composed of the RS485 cable temperature monitoring network composed of wireless temperature monitoring network or through GPRS module [4].

\section{Monitoring Main Station}

Monitoring main station have two IBM servers, a front-end processor for receiving on-scene data; another data server for stored field data and WEB access. Front-end based Microsoft WINSERVER2003 system development, the use of $\mathrm{C}++$ programming language developed main station service center software, using TCP / IP protocol and on-site temperature monitor communications.[5] This data servers using CENTOS6.0 development, use MYSQL data storage the data. Monitor function main station as follows:

\section{1) Data Server}

Mainly used for real-time data processing and storage equipment and system parameters, processing, storage and management of historical data.

\section{2) Front-end processor}

Front-end processor is used to receive data from the field 
temperature monitor, pre-processing the data (such completion of the Statute of the conversion processing); send control operations to temperature monitor on, download the data commands and the data.

\section{SYSTEM APPLICATIONS}

\section{A. Monitoring Sites Selected}

The system is applied to Inner Mongolia Bayannur $10 \mathrm{kV}$ distribution transformer, the high voltage side of the transformer and the low-pressure side of the point of contact parts due to the poor quality of the joint, the contact point of partial discharge, insulation aging, the contact resistance is too large and transformer overloading, often caused by power outage accident or transformer damage accident. Power Supply Bureau of distribution transformers on-site survey, analysis, and selected 30 sets of load distribution transformers as a test object. Each transformer installed a temperature monitor, power supply module and seven wireless temperature sensors. Use of mobile wireless public network, set up a monitoring master for the receipt and analysis of field data in Bayannur Electric Power Bureau.

\section{B. System Installation}

Carried out before installation, and technical personnel need to tidy up the technical data of the 30 distribution transformers. Determine the installation location and installation of wireless temperature sensor, temperature monitor. Temperature sensor should be based on the shape of the temperature measurement points to determine the installation: general temperature measurement points both flat and curved surfaces. Plane of temperature measurement points are generally an activator complex structures glue fixed sensor fixed should be measured with a rag to wipe clean, then spray on a little used in conjunction with structural adhesive activator, then the sensor temperature measurement surface coated with a structural adhesive stick to the measured point, press and hold the sensor by hand for about a minute or so let go, the sensors cannot withstand any pressure within 24 hours.[6]

Surface temperature measurement points are generally fixed sensor hoop (Fig. 3). Hoop production of materials for steel, outside the black anti-rust paint, installation First, choose the right under the surface diameter hoop, then the wireless temperature sensors embedded in the hoop, the hoop distraction with specialized tools, and then caught in the measurement points (Fig. 4). It should be noted here that the sensor antenna should be installed and then the sensor is installed, avoid collisions lead to the antenna damaged or broken sensor installation process.

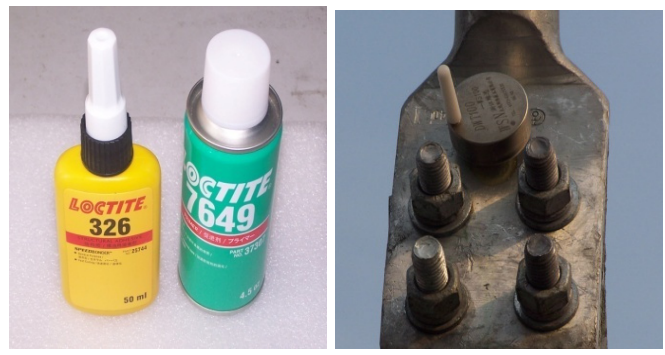

Fig. 3. Temperature sensor installation method

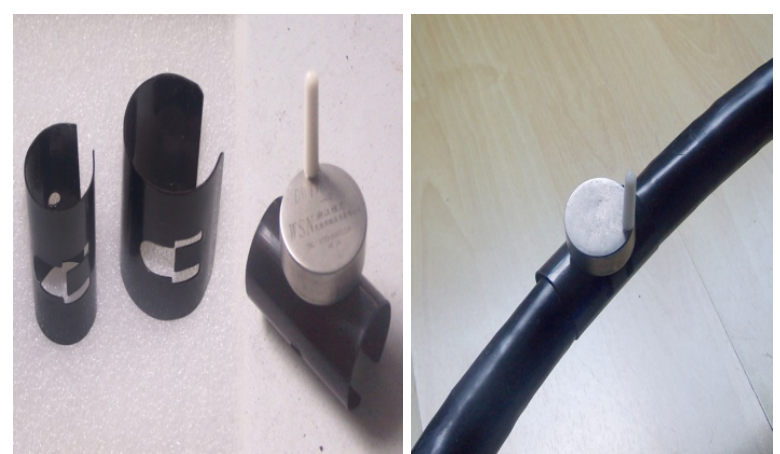

Fig. 4. Temperature sensor installation method

\section{Main Station Data Show}

Computer through the WEB way connected to the data server, you can see the main page of the temperature monitoring system, as shown in the figure, and the main page of the system shows the highest temperature value of the contact point of each transformer. Through the main interface can be any of the running of a transformer operating temperature versus time query. Remote configuration through the main page of the temperature monitor set the temperature acquisition interval, the alarm threshold. [7]Through the main page of the site you can easily add or remove. The main station can be set according to the temperature curve temperature alarm value of $75^{\circ} \mathrm{C}$. Once the temperature is above the warning value, it will send an alarm signal, through the analysis of the temperature and the monitoring of the contact point, the staff can determine whether the accident and take appropriate measures for the power outage maintenance [8].

\section{System Application}

\section{1) Field measurements}

June 12, 2012; high temperature; wireless temperature measurement acquisition data measurements: An $110 \mathrm{kV}$ substation has a $10 \mathrm{kV}$ line. An isolation switch a phase contact point generates heat temperature of $98^{\circ} \mathrm{C}$ on the line. By examining the staff found that the point of contact with the wires of high voltage isolation switch contact head screws crack, causing the point of contact resistance increases, the temperature rises. The fixing screws generate heat phenomenon eliminate.

\section{2) Field measurements}

August 7, 2012; high temperature; wireless temperature measurement acquisition data, measurement results: An $110 \mathrm{kV}$ substation has a $10 \mathrm{kV}$ line. Government office building distribution transformer secondary cable A low-pressure contact points generate heat temperature of $122^{\circ}$ Staffs to reach the on-site inspection to found A phase connector and cable head connector prolonged overheating, has nearly blown state, only a small part of the contact, and the transformer secondary guide rod at the lugs oil spill traces phenomenon appears. Immediately, disconnect the power supply replacement parts staff to deal with the problem of oil leakage. Start the distribution transformer secondary side of the low pressure severe three-phase load imbalance due to the high temperature in summer air-conditioning load after staffs analysis, staff adjust the air conditioning load, three-phase current balance work. 


\section{3) Field measurements}

August 22, 2012; drizzle; an $110 \mathrm{kV}$ substation has a $10 \mathrm{kV}$ line. Building materials Road Haley tube $10 \mathrm{kV}$ distribution transformer cable head C-phase high temperature $118{ }^{\circ} \mathrm{C}$. Operating personnel on-site inspection found that rain infiltrated into the cable head, resulting in lower dielectric strength, causing partial discharge, some sheds have been burnt, to reach the critical point of the run. Immediately, the re-production of the cable head to restore power supply.

Through the application of the system, you can monitor the temperature gauge of the contact point of the distribution transformer, avoid transformer, the contact point of the column switch the blown transformer overload cause burning accidents occur due to high temperature. According to 2012 data, it can be seen, the contact point of the transformer temperature gauge caused power outage and transformer damage accidents annually damaged transformers and accessories direct economic losses of over 30 million. The loss of electricity caused due to maintenance: $280,000 \mathrm{kWh} /$ year, and maintenance for more than $150 \mathrm{~h}$, the average electricity price of 0.38 Yuan / kWh computer, the loss of power: 10.6 million. Through the installation of a wireless temperature monitoring system, with an average savings of expenses over 50 million, the significant economic benefits. Through the use of temperature monitoring system can monitor the temperature of the contact point of the transformer, the next step, will increase the transformer cable temperature monitoring, the perfect temperature monitoring system.

\section{CONCLUSION}

Wireless temperature measurement technology can fundamentally solve the contact point of the distribution transformer overheating and contact bad run problem. By analyzing the operational status of the monitoring of the distribution transformer coupling contacts and distribution transformers, to ensure the long-term operation of the transformer to avoid distribution transformers over the upload and contacts to overheat and cause power outage. Run for the distribution line monitoring and improve the scientific method and effective basis to ensure the transformer safe and reliable operation

\section{REFERENCES}

[1] Z. Y. Liu, Smart grid knowledge Reading, China Electric Power Press, Beijing, 2010, pp. 36-37.

[2] Z. Y. Liu, Smart grid knowledge Quiz, China, Beijing, China Electric Power Press, 2010, pp. 123-125.

[3] S. Q. Lu and Q. F. Li, "Research survey and prospects for the application in China of foreign micro-grid," Huazhong electric. vol. 2, pp. 156-59, May 2009.

[4] W. H. Long, "Practice effective distribution network equipment Condition based maintenance," Theoretical study of city construction, vol. 1, no. 9, pp. 18-19, October 2012.

[5] F. X. Li, "Distribution network online condition-based maintenance Techniques of Exploration," New technology and new products, vol. 1, no. 3, pp. 10-11, March, 2012.

[6] C. M. Ji and Y. Chen, "Condition-based maintenance management of distribution network equipment," Hubei Electric Power, vol. 4, no. 5, pp. 6-7, May, 2005.

[7] S. L. Weng and Z. Y. Wang, "Implementation of the strategy research carried out with the grid line condition-based maintenance," Journal of Huzhou Teachers College, vol. 3, no. 6, pp. 12-14,July, 2009.

[8] C. Y. Gao, "Domestic and foreign electrical equipment condition based maintenance and development Overview," Heilongjiang Science and Technology Information, vol. 3, no. 10, pp. 20, October, 2012.

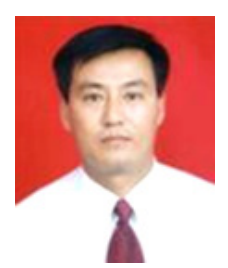

Su Yanfei was born in 1968, senior engineer, graduated from North China Electric Power University, Engineering Master.

He went to study in the U.S.in 2005. Based on the actual conduct of management and technological innovation, scientific and technological achievements of the national grid company and Technology Progress Award. Incumbent Inner engineering and technical experts. Main research direction is distribution network automation, scheduling management, smart grid.

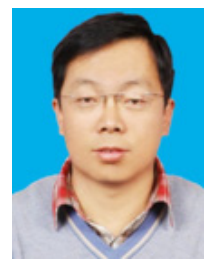

Zhao Chenxu was born in 1975, senior engineer, graduated from North China Electric Power University, Engineering Master.

He has been working in the distribution network planning, power grid construction, smart grid, over the years has participated in domestic and international power conference and published more than 20 papers, scientific and technological achievements won several innovation awards. Research direction is distribution network automation, scheduling management, smart grid.

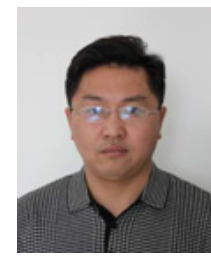

Xu Long was born in 1975, male, senior engineer, graduated from North China Electric Power University, Engineering Master.

He has been working in the distribution network planning, power grid construction, smart grid, over the years has participated in domestic and international power conference and published more than 20 papers, scientific and technological achievements won several innovation awards. Research direction is distribution network automation, scheduling management, smart grid.

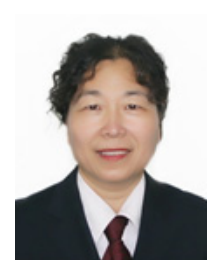

Yan Huanping was born in 1965, senior engineer, graduated from North China Electric Power University, Engineering Master.

She has been working in the distribution network planning, power grid construction, smart grid, over the years has participated in domestic and international power conference and published more than 10 papers, scientific and technological achievements won several innovation awards. Research direction is distribution network automation, scheduling management, smart grid.

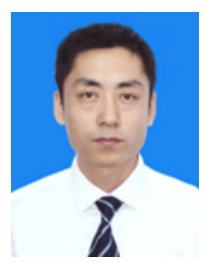

Xu Heng was born in 1978, senior engineer, graduated from North China Electric Power University, Engineering Master.

$\mathrm{He}$ has been working in the distribution network planning, power grid construction, smart grid, over the years has participated in domestic and international power conference and published more than 10 papers, scientific and technological achievements won several innovation awards. Research direction is distribution network automation, scheduling management, smart grid. 